\title{
GOVERNANÇA CORPORATIVA E DESEMPENHO DAS AÇÕES DE EMPRESAS DO SETOR COMERCIAL EM AMBIENTE DE CRISE ECONÔMICA
}

\section{CORPORATE GOVERNANCE AND PERFORMANCE OF COMPANY SHARES OF THE COMMERCIAL SECTOR IN AN ENVIRONMENT OF ECONOMIC CRISIS}

\author{
WILIEL FLORENCIO \\ Universidade Federal de Campina Grande. Endereço: Rua Princesa Isabel, \\ n. 29 | Estreito | 58800-778| Sousa/PB | Brasil. \\ (1) http://orcid.org/0000-0003-3412-3044 \\ wiliel@hotmail.com
}

\section{FABIANO FERREIRA BATISTA}

Universidade Federal de Campina Grande. Endereco: BR-230- Rodovia Governador Antônio Mariz, Km 466,5-BR 230 | 58800-000 | Sousa/PB | Brasil.

(D)http://orcid.org/0000-0003-2831-8478

fabianoferreirabatista@yahoo.com.br

\section{CRISTIANE QUEIROZ REIS}

Universidade Federal de Campina Grande. Endereço BR-230- Rodovia Governador Antônio Mariz, Km 466,5-BR 230 | 58800-000 | Sousa/PB | Brasil.

(D) http://orcid.org/0000-0003-2061-9575

profcristianereis@gmail.com

\section{RESUMO}

Em tempos de crise, empresas com sólida Governança Corporativa (GC) tendem a passar maior credibilidade e por isso enfrentam barreiras mais brandas no mercado de capitais. Desse modo, este estudo teve como objetivo analisar a relação da GC com o desempenho das ações, em períodos com e sem crise. Consideraram-se, para tanto, as empresas do setor comercial listadas na B3, com ações negociadas no período de 2015/2016 (com crise) e 2017/2018 (sem crise), resultando em uma amostra de 20 empresas, totalizando 319 observações. As empresas foram agrupadas por participação ou não em segmento diferenciado de GC (N1, N2 e NM) da B3 e analisadas por meio de estatística descritiva e regressão com dados em painel. Os resultados da estatística descritiva apontam que, em média, as ações das empresas do setor de comércio listadas na B3 "Com-GC" apresentaram melhores desempenhos do que aquelas "Sem-GC", resultado, provavelmente, da maior transparência das informações prestadas, do tratamento equitativo dos investidores e das medidas de monitoramento dos agentes exigidas pelas práticas de GC. Com relação ao modelo estimado, observou-se significância estatística e sinal positivo 
para as variáveis independentes lucro por ação (LPA) e a participação dos níveis diferenciados de governança corporativa ( $1 \%$ e $5 \%$ respectivamente). Já a variável que capta a crise econômica não se mostrou significante, não se podendo inferir que as práticas de GC são capazes de mitigar os efeitos negativos de crises econômicas no desempenho das ações.

Palavras-Chaves: Governança corporativa. Desempenho das ações. Crise econômica. Setor de Comércio.

\begin{abstract}
In times of crisis, companies with solid Corporate Governance (CG) tend to experience greater credibility and therefore face softer barriers in the capital market. Thus, this study aimed to analyze the relationship between $C G$ and the share performance, in periods with and without crisis. For this purpose, companies in the commercial sector listed on B3 were considered, with shares traded in the period 2015/2016 (with crisis) and 2017/2018 (without crisis), resulting in a sample of 20 companies, totaling 319 observations. The companies were grouped by participation or not in a differentiated CG segment (L1, L2 and NM) of B3 and analyzed using descriptive statistics and regression with panel data. The results of the descriptive statistics show that, on average, the shares of companies in the trade sector listed in B3 "With-CG" performed better than those "Without-CG", probably the result of greater transparency of the information provided, the equitable treatment of investors and the measures for monitoring agents required by $C G$ practices. Regarding the estimated model, there was statistical significance and a positive sign for the independent variables earnings per share (EPS) and the participation of different levels of corporate governance (1\% and 5\% respectively). However, the variable that captures the economic crisis was not significant, and it cannot be inferred that CG practices are capable of mitigating the negative effects of economic crises on the share performance.
\end{abstract}

Keywords: Corporate governance. Share performance. Economic crisis. Trade Sector.

\title{
1 INTRODUÇÃO
}

Com a necessidade de expandir as atividades e enfrentar a concorrência, as empresas necessitam captar recursos visando executar projetos que permitam atingir seus objetivos, seja o crescimento econômico-financeiro, o aumento na capacidade produtiva, a melhora da saúde financeira ou a implementação de novos projetos. O crescimento das organizações beneficia a economia nacional por gerar riquezas, emprego e renda, e por aumentar o consumo e a arrecadação de impostos, melhorando de forma geral a qualidade de vida das pessoas.

Segundo Garcia e Tavares (2017), à medida que as organizações se desenvolvem no mercado, é comum que passem a ser administradas não somente pelos seus proprietários, grupos familiares ou por pessoas cujos vínculos pessoais com o proprietário ultrapassam o ambiente organizacional, mas, também, por gestores (agentes) que recebem dos proprietários (acionistas) poderes para gerir os negócios.

Tanto a concentração de capital como a delegação de poderes aos gestores (agentes) podem originar conflitos de agência. Nesse caso, há duas situações distintas: a) os administradores tomam decisões visando maximizar seus próprios interesses em detrimento dos interesses dos acionistas; b) os acionistas majoritários, por terem maior poder sobre a organização, tomam decisões visando maximizar seus próprios interesses, desconsiderando os interesses dos acionistas minoritários. Dessa forma, tais conflitos ocorrem entre acionistas e administradores (principal-agente); e acionistas majoritários e acionistas minoritários (principalprincipal). 
Procurando minimizar este tipo de conflito e prestar informações mais transparentes aos investidores, as organizações têm adotado práticas de governança corporativa (GC), com o intuito de alinhar os interesses dos acionistas e acionistas/gestores, minimizando os prejuízos causados pelos conflitos de agência e garantindo maior segurança dos investimentos aos stakeholders.

No Brasil a B3 (Brasil, Bolsa e Balcão), antes denominada Bovespa (Bolsa de Valores de São Paulo), criou, em meados dos anos 2000, os níveis diferenciados de Governança Corporativa. Esses níveis são divididos em três, conforme as exigências impostas: Nível 1 (N1), com menor grau de exigência; nível 2 (N2); e novo mercado (NM), com maior grau de exigência (Geocze, 2010).

Segundo Clemente, Antonelli, Scherer e Cherobim (2014), a expectativa é que ao aderir a um nível de Governança Corporativa as empresas, por meio de maior transparência nas informações prestadas aos seus investidores, sejam vistas como mais confiáveis pelas partes interessadas, resultando em melhor desempenho dos preços das ações.

Srour (2005) comenta que as práticas de governança proporcionam menos volatilidade aos retornos de tal modo que, quando ocorrem choques negativos de retorno, as boas práticas de governança reduzem a tendência do controlador em desviar recursos, protegendo o valor da firma para os acionistas minoritários. Por outro lado, em momentos de choques positivos, as organizações de pior governança teriam desempenho relativo melhor, uma vez que haveria alteração mais significativa das tendências dos agentes ou controladores para reduzir desvios nos recursos e no valor de mercado da empresa. Percebe-se então que, em tempos de crise, empresas com sólida governança corporativa tendem a passar mais credibilidade e por isso enfrentam barreiras mais brandas no mercado de capitais.

Com base nessa discussão, pesquisas têm sido realizadas a fim de identificar se o desempenho dos ativos está relacionado à adoção dos níveis de Governança Corporativa (Aguiar, Corrar \& Batistella, 2004; Costa \& Camargos, 2006; Clemente et al., 2014; Francisco \& Santos, 2014; Silva, Santos \& Rodrigues, 2016; Freitas, Silva, Oliveira, de Aquino Cabra, \& dos Santos, 2018; Rocha, Contani \& Reco, 2017). A maioria dos resultados não confirma uma relação direta e significativa entre governança corporativa e desempenho das ações, sobretudo em diferentes contextos econômicos.

No entanto, conforme evidenciado por Silva et al. (2016), ao se analisar o desempenho das ações das empresas que congregam o setor bancário e industrial da BM\&FBOVESPA, podese observar que, em comparação com as empresas que não adotaram práticas diferenciadas de Governança Corporativa, as que o fizeram apresentaram melhor desempenho na relação entre risco e retorno.

É importante frisar que os diversos setores de atividades econômicas apresentam partes interessadas com diferença de 'aprendizado', ou seja, o nível de conhecimento de investidores e demais partes interessadas varia conforme os setores da economia. Nesse sentido, diante das alterações nas dinâmicas de mercado, as informações divulgadas pelas empresas podem influenciar as decisões dos investidores quanto à composição de suas carteiras, fazendo com que possam utilizar as informações divulgadas pelas companhias para tomar decisões que maximizem seus resultados (Francisco \& Santos, 2014; Bernardino, Peixoto, \& Nascimento, 2015; Silva et al., 2016).

O setor comercial é responsável por uma parcela representativa do Produto Interno Bruto (PIB). Sua representatividade vem aumentando no decorrer dos anos e seu valor adicionado apresentou maior crescimento que os demais setores econômicos, segundo dados do Instituto Brasileiro de Geografia e Estatística (IBGE) (2019). De acordo com Silva (2018), o desempenho do setor do comércio foi estimulado pelo aumento do consumo privado e absorve cerca de $20 \%$ da mão de obra, apesar dos empregos informais. É, portanto, um setor que se mostra mais sensível às variações econômicas, seja em termos de consumo ou de empregabilidade. 
Neste contexto, a questão que motivou esta pesquisa foi: em que medida a governança corporativa se relaciona com o desempenho das ações das empresas do setor comercial em um ambiente com e sem crise econômica? Desta forma, analisa-se a relação entre a GC e o desempenho das ações, negociadas no período de 2015/2016 (com crise) e 2017/2018 (sem crise), das empresas do setor comercial listadas na B3.

Este trabalho se mostra relevante em razão do papel da governança corporativa no desenvolvimento do mercado de capitais, que, por sua vez, contribui para melhorar o desenvolvimento econômico dos países e das organizações. Também mostra-se relevante por apresentar sobre o assunto um escopo diferente em relação às pesquisas existentes, pois se trata de um estudo comparativo entre os diferentes níveis de GC e os desempenhos das ações das empresas do setor de comércio, o que representa uma boa parcela do PIB do país, além de estar entre os principais setores agregados da B3. Além disso, existem poucos estudos com essa metodologia setorial que consideram o ambiente econômico mediando essa relação.

Por fim, estudos que tratam do assunto (Aguiar et al., 2004; Costa \& Camargos, 2006; Francisco \& Santos, 2014; Bernardino et al., 2015; Silva et al., 2016; Rocha et al., 2017) apresentam resultados mistos, mostrando que nem sempre as empresas com melhores práticas de Governança Corporativa apresentam melhores desempenhos, o que acresce interesse a este trabalho. Diante desse contexto, torna-se necessário realizar mais investigações para aprofundar o assunto.

\section{DISCUSSÃO TEÓRICA}

\subsection{Teoria da agência}

Partindo do pressuposto de que o crescimento de uma organização torna necessário delegar poderes a um terceiro para administrá-la, o aumento do número de proprietários (fugindo muitas vezes do formato de empresas familiares) gera um cenário no qual são necessários instrumentos para alinhar os interesses desse terceiro (agente), dos proprietários (principal) e dos demais interessados com quem uma entidade estabelece contratos.

A entidade então passa a ser vista como um nexo de contratos com esses diversos interessados, cada um com interesses diferentes e, por vezes, conflitantes, demandando um arcabouço teórico para gerenciar esses conflitos, bem como para definir quais interesses precisam ser levados em consideração pelos administradores (que também são parte interessada) e quais devem ser priorizados.

Jensen e Meckling (1976) chamam a atenção para a falta de uma teoria que explique como balancear os interesses conflitantes dos participantes de uma organização de modo a gerar resultados. Eles focam nos problemas decorrentes da separação entre posse e controle (problemas de agência) e nos custos inerentes ao processo (custos de agência), que acabam por acarretar assimetrias informacionais entre as partes, assim como risco moral, seleção adversa e outros problemas. Com o objetivo de analisar esses conflitos surge a Teoria da Agência.

Assim, não se pode ignorar a hipótese de que o agente possa agir de encontro aos interesses do principal, tornando necessário estabelecer incentivos, sejam financeiros ou mesmo mecanismos de monitoramento, como forma de garantir que não haverá conduta diferente da esperada.

Nesse contexto de conflitos, a teoria da agência ocupa-se em determinar qual seria o contrato mais eficiente para disciplinar a relação entre agente e principal (se um contrato baseado em desempenho ou em comportamento), assumindo que há, além do conflito, um desempenho facilmente mensurado, e que o agente é mais avesso ao risco do que o principal, visto que o primeiro não pode diversificar sua atividade, ao contrário do segundo.

Dentre as principais contribuições da Teoria da Agência, Eisenhardt (1989) relata o resgate da importância dos incentivos e do autointeresse em uma organização. Outra 
contribuição diz respeito à visão da informação como uma commodity, com seu respectivo custo e possibilidade de ser negociada e com incentivos para que a organização invista nela de modo a monitorar o agente, por exemplo, por meio de um conselho de administração. Dessa forma, sistemas de informação mais completos inibem o oportunismo gerencial e, consequentemente, resultam em menores remunerações por desempenho.

De forma geral, segundo Baker e Anderson (2011) a teoria da agência é o paradigma central das finanças e, sendo assim, indagam como o principal pode controlar e monitorar esses agentes a respeito do cumprimento de suas funções. Acrescentam que, ao passo que esses agentes passam a ser também proprietários de capital, diminui a tendência de tomarem decisões que prejudicarão o conjunto, uma vez que seus interesses estariam alinhados aos dos demais acionistas, havendo ainda outros incentivos para minimizar os possíveis conflitos.

\subsection{Governança corporativa}

Visando regular a relação entre gestores e acionistas, em particular, e entre todos os intervenientes da empresa como um todo, a governança corporativa abrange uma ampla gama de sistemas, processos e procedimentos com objetivo de proteger os interesses dos acionistas e consequentemente minimizar os custos de agência e maximizar o valor da organização.

Para Garcia e Tavares (2017) e Silveira (2002) a governança corporativa dispõe de práticas e mecanismos para monitorar e controlar as atividades do agente, de modo que ele tome decisões visando os interesses do principal. Portanto, espera-se que as práticas de governança minimizem os conflitos de agência e maximizem a riqueza da empresa e o retorno dos investidores.

Conforme definido pela Comissão de Valores Mobiliários (CMV) (2019), a governança corporativa é o conjunto de práticas que objetiva potencializar o desempenho de uma companhia ao proteger todos os stakeholders, tais como investidores, empregados e credores, facilitando o acesso ao capital, e tendo como princípios a transparência, equidade de tratamento dos investidores e prestação de contas.

Para Silveira (2004), a GC pode ser vista como um conjunto de mecanismos que visam maximizar a probabilidade dos investidores garantirem para si o retorno sobre seu investimento, pois o conjunto de mecanismos internos (conselho de administração, sistema de remuneração, estrutura de propriedade, transparência e política de dividendos) e externos (mercado de aquisição hostil, leis de proteção aos acionistas, cross-listings, auditoria externa e fiscalização de agentes de mercado) podem alinhar os interesses dos tomadores de decisão e dos acionistas, minimizando os prejuízos causados pelos conflitos de agência.

De acordo com Silva (2017), composta por um conjunto de princípios e práticas, a governança corporativa procura diminuir os conflitos de interesse entre os diferentes agentes da companhia (conflitos de agência), com a finalidade de reduzir o custo de capital e maximizar o valor da organização e o retorno aos seus investidores.

Em um cenário de turbulência, volatilidade, incertezas e maior integração econômica e financeira, Camargos e Barbosa (2006) afirmam que a GC tem-se mostrado importante e eficaz para muitas organizações que almejam melhorar sua imagem no mercado, maximizar o valor das ações, adquirir vantagens competitivas (como a redução do custo de capital), proporcionar maiores retornos para seus investidores e obter maior transparência em seus negócios. Segundo Fischer (2012), a governança corporativa pode se traduzir em instrumento ou mecanismo de proteção ao investidor em períodos de fortes crises.

Investidores tendem a ignorar a falta de uma boa governança corporativa durante um período de crescimento econômico. Entretanto, quando uma crise se inicia e os retornos esperados diminuem de forma significativa, eles passam a considerar as fraquezas de governança, especialmente em países nos quais há fraca proteção aos direitos dos acionistas minoritários (Liu, Uchida \& Yang, 2012). Um dos motivos pelos quais alguns países e empresas 
se comportam melhor que outros em períodos de crise envolve as diferenças na força das instituições legais e na estrutura dos mecanismos de governança que previnem a expropriação dos acionistas minoritários.

É nesse sentido que se insere a discussão da relação entre a governança corporativa e o desempenho empresarial, haja vista sua capacidade de sinalizar aos investidores maior confiabilidade das práticas desenvolvidas pela organização, que passa a exigir menor taxa de retorno, traduzindo-se em menor custo de capital e maior liquidez no mercado (Camargo \& Barbosa, 2006).

Quando uma companhia adere a práticas de governança corporativa, dado o compromisso com maior transparência na comunicação de informações internas ao mercado, acaba por reduzir a assimetria informacional e ser mais bem precificada pelos investidores, resultando em melhor desempenho dos preços das ações (Clemente et al., 2014). Além disso, diante de eventos que resultem em choques negativos no retorno, reduzem-se os incentivos percebidos pela gestão e pelos acionistas controladores de apropriação dos recursos dos acionistas minoritários, enquanto em momentos de choques positivos, eles inclinam-se a promover incremento no desempenho (Srour, 2005). Ou seja, em tempos de crise, empresas com sólida governança corporativa tendem a passar melhor credibilidade e por isso enfrentam barreiras mais brandas no mercado de capitais.

Rajan e Zingales (1998) relatam que a demanda dos investidores por práticas de governança corporativa é menor em contextos de prosperidade econômica. No entanto, em períodos de crise, a demanda aumenta, e é comum desfazerem suas posições em países nos quais há pouco comprometimento legal entre os acionistas e o controlador, afetando ainda mais o desempenho das empresas nesse contexto.

\subsection{Governança corporativa no Brasil}

Para Rossetti e Andrade (2014) e Garcia e Tavares (2017), diferente da governança corporativa existente nos Estados Unidos, que se expandiu para tentar solucionar os conflitos de interesse entre acionistas e agentes, a GC no Brasil começou a ganhar corpo quando os investidores de países desenvolvidos passaram a aumentar seus investimentos para além de suas fronteiras. Assim, eles começaram a pressionar os mercados de ações dos países emergentes (dentre eles, o Brasil) por uma administração mais transparente. Visando estimular o interesse dos investidores e valorizar as companhias, as empresas começam a adotar boas práticas de governança.

Em resposta às necessidades de crescimento e à diversificação do mercado brasileiro, entre elas a necessidade de igualdade de direitos entre acionistas minoritários e majoritários, de uma estrutura de conselho adequada e qualificada e de maior transparência das informações prestadas pelas companhias, a Bovespa criou os segmentos especiais de listagem: Novo Mercado, Nível 2 e Nível 1. A adesão a um dos níveis diferenciados de governança é voluntária e deve ser feita pela assinatura de um contrato específico, assumindo o compromisso de adotar as exigências impostas por cada nível.

Embora existam alguns parâmetros iguais para as diferentes listagens, quanto maior o nível, maiores os padrões de governança que devem ser adotados, agregando valor à companhia e atraindo mais investidores, uma vez que as boas práticas de governança aumentam a credibilidade da empresa e diminuem os problemas de agência. Conforme Besarria et al. (2015), os níveis diferenciados de governança corporativa atraem investidores para as organizações, geram valor para a companhia, diminuem o custo de capital e consequentemente ocasionam maior rentabilidade, uma vez que melhorar a qualidade das informações prestadas pelas organizações e ampliar os direitos societários reduz as incertezas no processo de avaliação e de investimento e, por conseguinte, o risco.

Apesar de os custos para as organizações aderirem a um dos segmentos diferenciados de GC, Pitzer (2011) ressalta que a obtenção de retorno, pela adesão dos controles diferenciados de 
GC, é um forte motivador para as empresas, pois esse retorno pode significar maior liquidez das ações, melhor avaliação do mercado, maior preço das ações, entre outros. Para Aguiar et al. (2004), quanto mais eficiente é a GC, mais interessante torna-se a empresa sob a ótica do investidor, pois ele terá maior segurança na tomada de decisão.

Diante desse contexto, espera-se que, ao se enquadrarem em um nível mais elevado de GC, as empresas apresentem melhor desempenho frente às de nível inferior, pois todos os mecanismos estabelecidos têm como finalidade melhorar a qualidade das informações prestadas pelas empresas de capital aberto a seus acionistas, bem como ampliar os direitos societários que diminuem a incerteza no processo de avaliação de risco do investimento. Assim, reduzir tais incertezas tende a aumentar a precificação da ação, o que por sua vez diminui a volatilidade dos ativos fortalecendo o mercado de capitais como uma opção de fonte de investimentos.

\subsection{Estudos correlatos}

Os estudos que buscam investigar a relação entre a GC e o desempenho de companhias apresentam conclusões mistas, a depender do setor e período considerados.

Para Srour (2005) a governança corporativa afeta diretamente os retornos das firmas em períodos de crise. Segundo o autor, foram encontradas evidências que comprovam que em períodos de crise as empresas com melhores práticas de governança (Nível 2 e Novo Mercado) apresentaram queda relativamente menor de seus retornos e menor volatilidade frente às classificadas nos outros níveis.

Francisco e Santos (2014) buscaram verificar se a assunção de níveis mais elevados de governança corporativa proporciona às empresas do setor de energia elétrica do Brasil melhor desempenho em comparação com as classificadas em níveis inferiores entre o período de junho de 2009 até 30 de junho de 2011. Os resultados não confirmaram a expectativa inicial de que as empresas de níveis mais elevados apresentassem melhores desempenhos.

Para alguns autores (Bernardino et al., 2015; Silva et al., 2016) o setor pode influenciar positivamente a relação entre o nível de governança corporativa e o desempenho das ações. Possivelmente isso ocorre em função desses setores apresentarem diferentes tipos de stakeholders, com diferentes tipos de conhecimento. Assim, é possível que exista diferença de "aprendizado" dos stakeholders (nível de conhecimento de investidores e demais partes interessadas) entre os setores da economia, e as informações divulgadas por meio dos mecanismos de GC podem influenciar as decisões dos investidores e dos gestores sobre melhorias administrativas que resultem em melhores resultados.

Silva et al. (2016), a partir da comparação risco versus retorno, ao pesquisarem sobre o desempenho (no período de 2009 a 2014) das empresas que congregam os setores industriais e bancários da BM\&FBOVESPA, concluem que, em média, as empresas que adotaram práticas diferenciadas de governança corporativa no processo de gestão tendem a apresentar melhor desempenho frente às empresas que não as adotaram.

Ao analisar a correlação entre governança corporativa e desempenho das ações, orientados pelo propósito de aferir em que grau a classificação do nível de GC (N1, N2 e NM) e o comportamento de ações do setor de consumo e varejo listadas na B3 (Brasil, Bolsa, Balcão) podem ser mutuamente influenciados, Rocha et al. (2017) verificaram que as empresas listadas com GC não apresentaram retornos estatisticamente superiores às tradicionais. Contudo, empresas com GC tiveram menor risco se comparadas às empresas listadas no segmento tradicional.

Freitas et al. (2018) analisaram a influência da GC no desempenho econômico-financeiro dos bancos listados na B3, comparados em um ambiente com e sem crise econômica. Segundo os autores, há uma relação significante, porém negativa, entre GC e desempenho, o que leva à rejeição da hipótese de que participar de segmentos especiais de governança corporativa da B3 
influencia positivamente o desempenho dos bancos. Existiria uma relação não significante entre desempenho e crise, e significante entre GC e crise.

Do exposto, percebe-se que há diversas possibilidades de investigação a respeito do tema, uma vez que os estudos desenvolvidos apresentam diferentes resultados, sobretudo quando se trata de diferentes setores da economia e diferentes contextos econômicos que tendem a influenciar, simultaneamente às práticas de GC, o desempenho das empresas

\section{PROCEDIMENTOS METODOLÓGICOS}

Para realizar esse estudo foram utilizadas empresas do setor de comércio que mantiveram ações negociadas no período de 2015 a 2018, conforme classificação da B3 e da Comdinheiro.

Desse modo, com a decisão metodológica de trabalhar com amostra estratificada de um mesmo setor, objetivou-se verificar se a adoção de boas práticas de governança consegue minimizar os efeitos da crise no desempenho das ações das empresas, dado que empresas de um mesmo setor estão sujeitas às mesmas condições macroeconômicas e legais. Portanto, as diferenças de desempenho entre elas podem ser justificadas, aparentemente, pelas características e resultados da gestão de cada entidade.

A metodologia setorial também é justificável, pois, conforme já evidenciado (Bernardino et al., 2015; Silva et al., 2016) os setores da economia apresentam públicos de interesse com diferentes níveis de conhecimento e maturidade e as informações divulgadas pelas empresas podem influenciar as decisões dos investidores diante das alterações nas dinâmicas e das melhorias gerenciais que venham a maximizar o desempenho da organização.

A amostra compreende o período entre 2015 e 2018 por dois motivos: primeiramente, para buscar evidências atuais sobre o assunto; segundo, por se tratar do período de tempo mais prolongado de recessão no PIB (crise econômica 2015/2016) do país nos últimos 10 anos, ao qual se seguiu período de avanços (sem crise 2017 e 2018), conforme evidenciado na Figura 1.

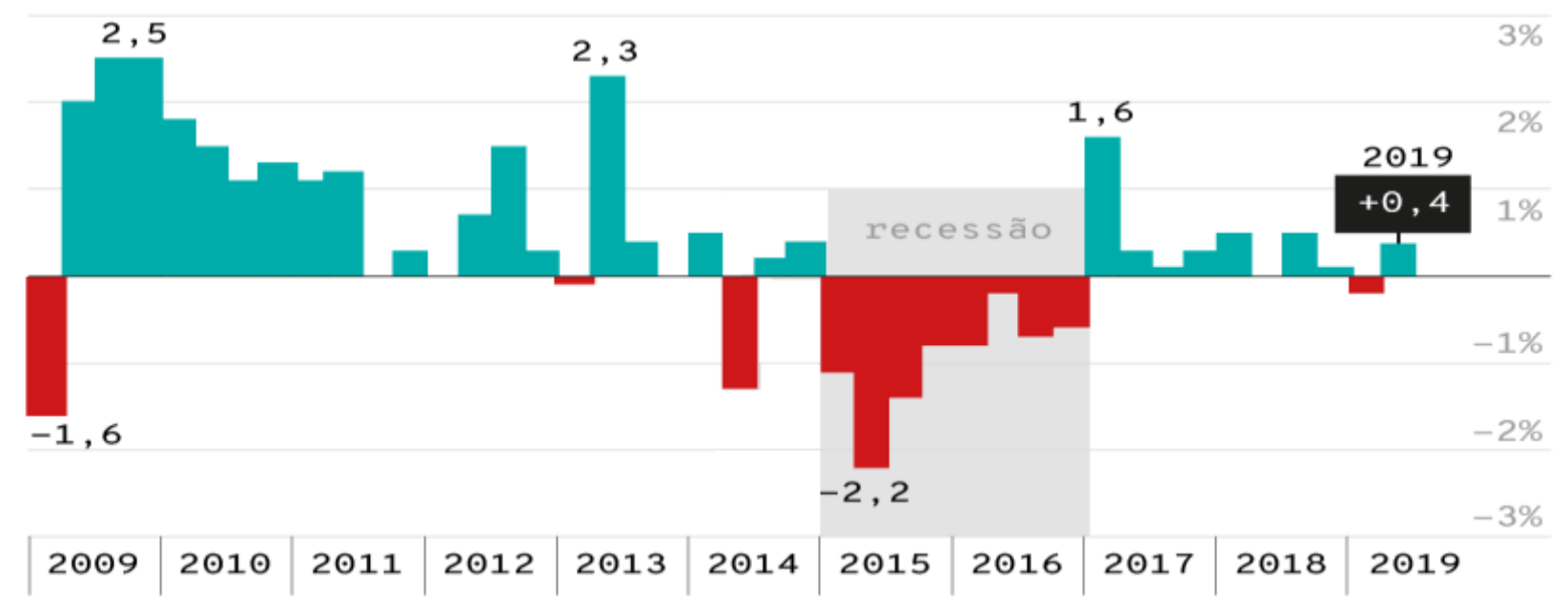

Figura 1. PIB trimestral do Brasil em 10 anos (2009 a 2018).

Fonte: PIB do Brasil: histórico e evolução em gráficos - gazeta do povo.

Foram identificadas inicialmente 26 companhias, entre as quais três não estavam listadas na B3, uma não tinha ações negociadas durante todo o período, uma não tinha ações negociadas no período de crise e uma não tinha ações negociadas na maioria dos trimestres. A amostra final foi composta por 20 companhias e 319 observações, conforme a Tabela 1. O número final de observações resulta do cálculo dos retornos trimestrais das companhias. Apenas uma empresa não apresentou ações negociadas na bolsa no primeiro trimestre de 2015. 
Tabela 1

\section{Definição da Amostra}

\begin{tabular}{lcc}
\hline Critérios de delimitação da amostra & Total & Observações \\
\hline $\begin{array}{l}\text { Empresas do Setor de Comércio com ações negociadas e dados disponíveis na } \\
\text { Comdinheiro }\end{array}$ & 26 & 415 \\
$\begin{array}{l}\text { Exclusões } \\
\text { (-) Empresas sem ativos reconhecidos na B3 }\end{array}$ & 3 & 48 \\
$\begin{array}{l}\text { (-) Empresas sem ações negociadas durante todos ou maior parte dos trimestres } \\
\text { de } 2015 \text { a } 2018\end{array}$ & 3 & 48 \\
Total da amostral final & $\mathbf{2 0}$ & $\mathbf{3 1 9}$ \\
\hline
\end{tabular}

Fonte: Elaborado com base nos dados das empresas estudadas, disponíveis nas bases de dados da Comdinheiro ${ }^{\circledR}$ e B3 (2019).

A coleta de dados foi realizada no site da B3 e no banco de dados da Comdinheiro. A amostra foi estratificada em dois subgrupos, a saber: empresas que participam de qualquer segmento diferenciado de GC (N1, N2 e NM) da B3 e empresas que não participam de nenhum dos segmentos. Das 20 empresas, seis não participam dos segmentos de GC, ao passo que as outras 14 participam nos seguintes níveis: uma empresa no N1, uma empresa no N2 e 12 empresas no NM. A segmentação permite comparar a eficiência entre o grupo com GC e o sem GC.

Para atender ao objetivo deste estudo, utilizaram-se modelos de pesquisadores que propõem analisar o desempenho das ações das empresas. Primeiro tomou-se como base a metodologia empregada por Rocha et al. (2017) para calcular os retornos de cada período, de acordo com a Equação 1. Optou-se por calcular o retorno trimestral do período para que pudesse coincidir com o período de divulgação do PIB.

$$
R_{i t}=\ln \frac{P_{i t}}{P_{i t-1}}
$$

Em que:

$R_{i t}=$ é o Retorno da ação da empresa i, no tempo $\mathrm{t}$

$P_{i t}=$ preço de fechamento da ação da empresa i, no tempo $\mathrm{t}$

$P_{i t-1}=$ preço de fechamento da empresa $\mathrm{i}$, no tempo $\mathrm{t}$ anterior

Com a finalidade de avaliar as possíveis interações entre crise, governança corporativa e desempenho, utilizaram-se dados em painel para estimar os coeficientes da regressão, conforme Equação 2.

$$
D E S E M P_{i t}=\beta_{0}+\beta_{1} L P A_{i t}+\beta_{2} d c_{i t}+\beta_{3} g c_{i t}+\varepsilon
$$

Em que:

$\operatorname{DESEMP} P_{i t}=$ desempenho das ações (retorno das ações) da empresa $\mathrm{i}$, no tempo $\mathrm{t}$, mensurado conforme Equação 1

$L P A_{i t}=$ lucro por ação da empresa $\mathrm{i}$, no tempo $\mathrm{t}$

$d c_{i t}=$ dummy de crise da empresa $\mathrm{i}$, no tempo $\mathrm{t}$, assumindo o número 1 , para os trimestres de 2015 e 2016 (período 'Com_Crise'), ou o número 0, para os dados referentes aos trimestres de 2017 e 2018 (período 'Sem_Crise') 
$g c_{i t}=$ dummy de governança corporativa, que assume o valor 1, se a empresa integra um dos níveis de GC da B3, ou o valor 0 , se ele não for integrante

Espera-se significância estatística e sinal negativo para $\beta_{2}$, denotando influência negativa dos períodos com crise no desempenho, e significância estatística e sinal positivo para $\beta_{3}$, denotando influência das práticas de GC no desempenho.

Em segundo momento, foi adicionada ao modelo uma variável interativa entre crise econômica e governança corporativa $\left(\mathrm{dc}^{*} \mathrm{gc}\right)$, obtida pelo produto das duas variáveis dummy independentes, estimando de forma incremental o papel das práticas de governança corporativa em mitigar os efeitos da crise econômica no desempenho empresarial. Chegou-se, pois, ao modelo de regressão representado pela Equação 3:

$$
\operatorname{DESEMP}_{i t}=\beta_{0}+\beta_{1} L P A_{i t}+\beta_{1} d c_{i t}+\beta_{3} g c_{i t}+\beta_{4}\left(d c_{i t} * g c_{i t}\right)+\varepsilon
$$

Com isso, a variável de interesse desse estudo é a $g c$ e sua interação com $d c$. Para o coeficiente $\beta_{3}$, espera-se significância estatística e relação positiva e para o coeficiente $\beta_{4}$, que analisa a relação entre o desempenho de empresas e a utilização das práticas de governança corporativa em períodos de crise, comparadas àquelas que não se valeram dessas práticas, espera-se significância estatística e sinal positivo.

\section{APRESENTAÇÃO E ANÁLISE DOS RESULTADOS}

Nesta seção são retratados os resultados da análise dos dados. Inicialmente, realizou-se análise descritiva da variável "retorno das ações" das empresas do setor de comércio com e sem governança corporativa, em diferentes cenários econômicos.

Tabela 2

\section{Estatística descritiva das variáveis}

\begin{tabular}{lcc}
\hline & Com-Crise (2015-2016) & Sem-Crise (2017-2018) \\
\hline Média & $-0,013753$ & 0,024318 \\
Do setor & $-0,0248$ & $-0,02442$ \\
Sem-gc & $-0,00912$ & 0,045206 \\
Com-gc & & \\
Desvio padrão & 0,290469 & 0,2647368 \\
Do setor & 0,272669 & 0,317882 \\
Sem-gc & 0,298686 & 0,236937 \\
Com-gc &
\end{tabular}

Fonte: Elaborado com base nos dados das empresas estudadas, disponíveis nas bases de dados da Comdinheiro ${ }^{\circledR} \mathrm{e}$ B3 (2019).

Com base nas estatísticas descritivas dos retornos das ações apresentadas na Tabela 2, observa-se que a média das empresas listados no período 'Sem-Crise' $(0,024318)$ apresenta retorno das ações superior à média do período 'Com-Crise' $(-0,013753)$. Ou seja, os retornos das ações foram reduzidos no período de crise econômica. Tal evidência vai ao encontro da perspectiva de Freitas et al. (2018), segundo o qual em um ambiente de crise econômica há uma tendência de redução do desempenho e da confiança entre os agentes econômicos.

Ao avaliar a média dos retornos das ações nos tipos de listagem, as empresas que integram algum segmento especial de governança corporativa da B3 (Com-GC) apresentam retornos superiores aos retornos das empresas que não o integram (Sem-GC). Diante dessa análise foi possível encontrar uma associação entre o retorno das ações por meio dos ganhos ou 
perdas de capital e o nível de governança corporativa das empresas listadas no setor de comércio da B3. Os resultados dessa variável para o setor de comércio vão ao encontro das evidências obtidas por Silva et al. (2016).

Tanto no período 'Com-Crise' como no período 'Sem-Crise' a média de retorno das ações das empresas do setor de comércio com 'Com-GC' foi superior à das empresas 'Sem-GC'. Esse resultado vai contra o estudo de Freitas et al. (2018) sobre o setor bancário. Pode-se também observar que nos dois períodos as empresas que não se enquadravam em nenhum nível de governança corporativa apresentaram retornos negativos em geral.

Em média, segundo os resultados da Tabela 3, que contém uma análise de todo o período, pode-se perceber que as ações das empresas do setor de comércio listadas na B3, enquadradas em nível diferenciado de governança corporativa $(0,018044)$, apresentaram melhor desempenho (retorno) do que as ações das empresas sem GC (-0,024608). Com isso, por meio da análise descritiva pode-se perceber que a governança corporativa está positivamente relacionada ao desempenho das ações.

Tabela 3

\section{Estatística descritiva de todo o período}

\begin{tabular}{lcc}
\hline Segmento & Média & Desvio Padrão \\
\hline Sem-gc & $-0,024608$ & 0,2948010 \\
Com-gc & 0,018044 & 0,2703538 \\
\hline
\end{tabular}

Fonte: Elaborado com base nos dados das empresas estudadas, disponíveis nas bases de dados da Comdinheiro ${ }^{\circledR} \mathrm{e}$ B3 (2019).

Posteriormente, para fortalecer as análises, uma vez que somente a análise descritiva não é suficiente para testar as hipóteses formuladas, foram estimados, por meio de dados em painel, os parâmetros para os modelos representados nas Equações 2 e 3. Em ambas as estimativas os testes apontaram que o MQO era o método mais adequado.

Na Tabela 4 estão os parâmetros estimados para o modelo 1 (Equação 2):

Tabela 4

Validação do Modelo 1

\begin{tabular}{lccc}
\hline & \multicolumn{2}{c}{$\begin{array}{c}\text { MQO agrupado, usando 319 observações } \\
\text { Variável dependente }: \boldsymbol{R}\end{array}$} & $\boldsymbol{g c}$ \\
\hline$\beta \mathrm{i}$ & $\boldsymbol{L P A}$ & $\boldsymbol{d}$ & 0,0742 \\
Erro-padrão & 0,0307373 & $-0,0336906$ & 0,0349 \\
Razão t & 0,00953998 & 0,0306674 & 2,127 \\
p-valor & 3,222 & $-1,099$ & 0,0342 \\
Sinal (Sig.) & 0,0014 & 0,2728 & $* *$ \\
\hline $\mathrm{R}^{2}=0,041278$ & $* * *$ & & \\
\hline
\end{tabular}

Teste para diferenciar grupos de interceptos no eixo $\mathrm{x}=0$ - Hipótese nula: os grupos têm a mesma intercepção no eixo $\mathrm{x}=0$. Estatística de teste: $\mathrm{F}(3,315)=4,520747$ com P-valor(F) 0,004032

\begin{tabular}{|c|c|c|}
\hline Conclusão & Fixo & \\
\hline Teste de Não Linearidade ${ }^{a}$ & 0,190887 & Hipótese nula: a relação é linear (não rejeitada) \\
\hline Ramsey RESET $^{b}$ & 0,635548 & $\begin{array}{l}\text { Hipótese nula: a especificação é adequada (não } \\
\text { rejeitada) }\end{array}$ \\
\hline Durbin-Watson $^{c}$ & 2,033196 & \\
\hline Teste de White ${ }^{d}$ & 0,185201 & $\begin{array}{l}\text { Hipótese nula: sem heterocedasticidade (não } \\
\text { rejeitada) }\end{array}$ \\
\hline
\end{tabular}




\begin{tabular}{|c|c|c|}
\hline Jarque Bera ${ }^{e}$ & $1,50206 \mathrm{e}-08$ & $\begin{array}{l}\text { Hipótese nula: o erro tem distribuição Normal } \\
\text { (rejeitada) }\end{array}$ \\
\hline
\end{tabular}

Nota: Na tabela foi evidenciada a estatística dos testes, cuja significância é apresentada por meio de letras sobrescritas.

Fonte: Elaborado com base nos dados das empresas estudadas, disponíveis nas bases de dados do Comdinheiro e B3.

*Significativo a $10 \%$. **Significativo a $5 \%$. *** Significativo a $1 \%$.

a Testa a hipótese de existência de relação linear (apresentado o p-valor)

b Testa a hipótese de especificação adequada - não omissão de variáveis relevantes (apresentado o p-valor).

${ }^{\mathrm{c}}$ Testa a hipótese de autocorrelação dos resíduos.

d Testa a hipótese de homoscedasticidade; na presença da qual os erros-padrão foram estimados com correção para heterocedasticidade de White. Rejeitou-se ainda a hipótese de multicolinearidade, dado que todas as variáveis apresentaram estatística variance inflation fator (FIV) inferior a 10 (apresentado o p-valor).

e Testa a hipótese da normalidade dos resíduos (apresentado o p-valor). De acordo com o teorema do limite central e considerando que foram utilizadas 319 observações, relaxou-se esse pressuposto, aliado ao fato de que os parâmetros não serão utilizados para realizar previsões (inferências).

Fonte: Elaborado com base nos dados das empresas estudadas, disponíveis nas bases de dados da Comdinheiro $^{\circledR}$ e B3 (2019).

No caso do modelo 1, os resultados apontam para uma relação positiva e significante a $5 \%$ entre a GC e o retorno das ações. Ou seja, participar de segmentos especiais de governança corporativa da B3 influencia positivamente o desempenho das ações das empresas do setor de comércio listadas na B3. De forma geral, os resultados demonstram que as empresas que adotaram práticas diferenciadas de governança corporativa tendem a apresentar melhor desempenho, em comparação com aquelas que não as adotaram, como se observa em Silva et al. (2016).

As variáveis independentes de lucro por ação (LPA) e a dummy de governança corporativa são estatisticamente significantes a $1 \%$ e $5 \%$, respectivamente. Já a variável crise econômica não se mostrou significante. Portanto, não há diferença estatisticamente significativa entre os retornos nos anos de crise em comparação aos anos sem crise. Pode-se então inferir que o LPA e a governança corporativa têm relação com o desempenho, medido pelo retorno das ações das empresas do setor de comércio, independentemente da situação econômica.

Adicionalmente, analisou-se a regressão com o incremento da variável interativa entre as dummies independentes de crise econômica e a governança corporativa $(\mathrm{dc} * \mathrm{gc})$, conforme o modelo 1 (Equação 2). Os resultados estão na Tabela 5:

Tabela 5

Validação do Modelo 2

\begin{tabular}{lcccc}
\hline & $\boldsymbol{L P A}$ & $\boldsymbol{d} \boldsymbol{c}$ & $\boldsymbol{g} \boldsymbol{c}$ & $\boldsymbol{d} \boldsymbol{c}^{*} \boldsymbol{g} \boldsymbol{c}$ \\
\hline$\beta \mathrm{i}$ & 0,0309604 & 0,00823357 & 0,1040 & $-0,0596553$ \\
Erro-padrão & 0,00954642 & 0,0562201 & 0,0484 & 0,0670 \\
Razão t & 3,243 & 0,1465 & 2,15 & $-0,8899$ \\
p-valor & 0,0013 & 0,8837 & 0,0323 & 0,3742 \\
Sinal (Sig.) & $* * *$ & & $* *$ & \\
\hline $\mathrm{R}^{2}=0,043689$ & $\mathrm{R}^{2}$ ajustado $=0,031507$ & \multicolumn{2}{c}{ Critério de Akaike $=83,4829$} \\
\hline
\end{tabular}

Teste para diferenciar grupos de interceptos no eixo $\mathrm{x}=0$ - Hipótese nula: os grupos têm a mesma intercepção no eixo $\mathrm{x}=0$. Estatística de teste: $\mathrm{F}(4,314)=3,586289$ com $\mathrm{P}$-valor(F) 0,00707

\begin{tabular}{lcl}
\hline \multicolumn{1}{c}{ Conclusão } & Fixo & \\
\hline Teste de Não Linearidade $^{\mathbf{a}}$ & 0,192025 & Hipótese nula: a relação é linear (não rejeitada) \\
Ramsey RESET $^{\mathbf{b}}$ & 0,525702 & Hipótese nula: a especificação é adequada (não rejeitada)
\end{tabular}


Durbin-Watson ${ }^{\mathrm{c}}$

Teste de White ${ }^{d}$

Jarque Bera ${ }^{\mathbf{e}}$
2,038433

0,0409775 Hipótese nula: sem heterocedasticidade (não rejeitada a 10\%;

rejeitada a 5 e $1 \%$ )

3,01E-08 Hipótese nula: o erro tem distribuição Normal (rejeitada)

Fonte: Elaborado com base nos dados das empresas estudadas, disponíveis nas bases de dados da Comdinheiro ${ }^{\circledR}$ e B3 (2019).

A variável interativa de crise econômica e governança corporativa ( $\mathrm{dc}^{*} \mathrm{gc}$ ) não se mostrou estatisticamente significante no modelo. Ou seja, as empresas com níveis diferenciados de governança corporativa não apresentam diferenças estatisticamente significantes em comparação com as que não integram esses níveis, quando considerado o ambiente com crise. Os outros resultados não tiveram alterações em relação à regressão da Tabela 4.

Ainda que sejam comuns resultados que apontem para uma relação positiva entre essas variáveis, nem sempre a prática reflete a teoria aplicada no que tange à expectativa de que as empresas com melhores práticas de GC apresentem melhores desempenhos. Alguns trabalhos contrariam essa lógica, apresentando resultados nulos ou relação negativa entre a GC e o desempenho, a exemplo de Freitas et al. (2018), Costa e Camargos (2006) e Rocha et al. (2017).

Os dados obtidos atestam a discussão teórica deste trabalho, segundo a qual a governança corporativa mitiga os riscos relacionados ao negócio e os oriundos de conflitos de interesse entre agente-principal e acionistas minoritários (principal-principal), além de maximizar o desempenho por meio de maior retorno patrimonial decorrente de maior transparência, tratamento equitativo entre os proprietários, accountability e responsabilidade corporativa, princípios da governança corporativa e demandas dos participantes do mercado, sobretudo em mercados emergentes caracterizados por fraca proteção ao acionista.

\section{CONSIDERAÇÕES FINAIS}

O mercado de capitais é um dos grandes aliados no desenvolvimento econômico de um país. Para fortalecê-lo se faz necessário alocar recursos para as empresas de diversos setores que estejam aptas a receber tais investimentos. Caso essas entidades aufiram ganhos progressivos, a economia nacional se beneficia, pois mais riqueza é gerada.

Para que se tenha um mercado de capitais forte e operante, similar aos dos países desenvolvidos, são necessários investimentos que o tornem mais líquido, além de proteção ao investidor, seja por meio de leis ou de práticas de governança que proporcionem a segurança necessária para atrair capital.

O investidor que escolhe investir no mercado de ações tem como perspectiva um retorno maior para seu ativo, levando em consideração os riscos inerentes a sua escolha. Para tanto, a alocação dos recursos passa a ser orientada pela disponibilidade de informação sobre as opções de investimento que, essencialmente, precisam ser confiáveis. Do contrário, sem meios que garantam a confiabilidade das informações e que assegurem que todas as informações relevantes estão sendo divulgadas para minimizar assimetrias informacionais, esses investidores acabam exigindo maiores taxas de retorno e oferecendo desconto no valor empresarial, gerando prejuízos no seu desempenho.

Um dos principais argumentos para a criação dos níveis diferenciados de governança corporativa - Nível 1, Nível 2 e Novo Mercado - foi a mudança na imagem institucional da empresa, que seria provocada pelo cumprimento das rígidas normas de governança corporativa, gerando um ambiente de negociação que estimulasse, ao mesmo tempo, o interesse dos investidores - por meio de maior proteção - e a valorização das companhias.

A governança corporativa, portanto, parece ser fundamental para conferir segurança aos aportes de capital, além de ser uma ferramenta de controle e equidade de direitos e deveres, 
alinhando os interesses dos stakeholders e visando, com isso, o desenvolvimento da entidade e o retorno para os investidores, pois utilizar as melhores práticas de governança proporciona maior transparência nas decisões que norteiam a organização e nas informações fornecidas para a tomada de decisão.

No entanto, algumas pesquisas mostram resultados mistos, segundo os quais nem sempre empresas com melhores práticas de GC apresentam os melhores desempenhos. Fazem-se necessárias, portanto, maiores investigações sobre o assunto.

Diante desse contexto, este trabalho teve como objetivo analisar a relação entre governança corporativa e desempenho das ações das empresas do setor comercial listadas na B3, em um ambiente com e sem crise econômica.

Os resultados desta pesquisa estão alinhados aos preceitos teóricos segundo os quais as ações das organizações com práticas diferenciadas de governança corporativa tendem a apresentar melhores desempenhos, fruto provavelmente da maior transparência das informações prestadas, do tratamento igualitário dos investidores e de medidas de monitoramento dos agentes. Desse modo, respondendo à questão central desta pesquisa, as práticas de governança corporativa, representadas pelos níveis diferenciados, apresentam relação positiva com o desempenho das ações. No entanto, não foi possível afirmar, como se esperava, que tais práticas mitigaram o efeito negativo da crise econômica sobre o desempenho.

Sendo assim, esta pesquisa contribui para disseminar a importância de implementar boas práticas de GC como forma de proporcionar maior transparência e, consequentemente, maior engajamento dos stakeholders, uma vez que tais práticas refletem na percepção dos investidores sobre o risco atrelado ao investimento, como também colaboram com a divulgação de informações e sua posterior utilização na alocação de recursos dos investidores, conferindo melhor precificação dos ativos das empresas que adotam tais práticas e, de forma macro, maior liquidez do mercado.

Porém, vale salientar que as melhores práticas de governança corporativa não produzem por si mesmas melhor desempenho, pois não se trata de um modelo de negócios, mas de uma forma de geri-lo e fornecer sinais confiáveis ao mercado, sem necessariamente interferir nas decisões operacionais da corporação e em seus fundamentos econômicos.

Este estudo foi limitado principalmente pela pequena quantidade de empresas do setor pesquisado e pela indisponibilidade de informações necessárias à realização do estudo, resultando em redução da amostra.

Importante ressaltar que os resultados deste estudo são restritos à amostra e ao período investigado, não podendo ser generalizados para outros contextos setoriais ou econômicos que poderiam interferir nas variáveis empregadas. Portanto, as evidências encontradas e discutidas neste estudo devem ser consideradas em vista dos limites da metodologia aplicada, do período e da amostra utilizada.

Diante desse contexto, torna-se necessário salientar que a realização de outras pesquisas é importante para conferir maior profundidade ao tema. Elas podem considerar outros setores, período maior que abranja outras fases da economia, práticas específicas de governança, além de possível comparação do papel da governança corporativa em diferentes mercados.

\section{REFERÊNCIAS}

Aguiar, A. B., Corrar, L. J., \& Batistella, F. D. (2004). Adoção de práticas de governança corporativa e o comportamento das ações na Bovespa: evidências empíricas. Revista de Administração da Universidade de São Paulo, 39(4).

Baker, H. K., \& Anderson, R. (2011). Corporate governance: a synthesis of theory, research, and practice. The Robert W. Kolb series in finance. New Jersey: Wiley. 
Bernardino, F. F. M., Peixoto, F. M., \& Nascimento Ferreira, R. do (2015). Governança e eficiência em empresas do setor elétrico brasileiro. Revista Pretexto, 16(1), 36-51.

Besarria, C. N., Paula, Â. A., Araújo, B. S., Alves, J. N., Almeida, F. F., \& Monteiro, V. S. (2015). A qualidade das informações prestadas pelas empresas reduz os riscos de investimento? Uma análise empírica para os diferentes níveis de governança corporativa das empresas brasileiras. Race: revista de administração, contabilidade e economia, 14(1), 11-38.

Camargos, M. A. D., \& Barbosa, F. V. (2006). Evidência empírica do impacto da adesão aos níveis diferenciados de governança corporativa sobre o comportamento das ações na Bovespa. Encontro Nacional da Associação Nacional de Pós-Graduação e Pesquisa em Administração (Enanpad), 30.

Clemente, A., Antonelli, R. A., Scherer, L. M., \& Cherobim, A. P. M. S. (2014). O mercado brasileiro precifica a adesão e a migração aos níveis diferenciados de governança corporativa? Revista Base (Administração e Contabilidade) da UNISINOS, 11(2), 140-152.

Comissão de Valores Mobiliários (CVM) (2019). Recomendações da CMV sobre governança $\begin{array}{llllll}\text { corporativa. } & \text { Recuperado em junho, } 02 \text { de }\end{array}$ http://www.cvm.gov.br/export/sites/cvm/decisoes/anexos/0001/3935.pdf

Costa, A. R., \& Camargos, M. A. (2006). Análise empírica do impacto da adesão aos níveis diferenciados de governança corporativa da Bovespa sobre o retorno dos acionistas. REGE Revista de Gestão, 13(1), 31-42.

Eisenhardt, K. M. (1989) Building Theories From Case Study Research. The Academy of Management Review; 14 (4), 532-550.

Fischer, M. A. (2012). Governança corporativa analisada nos limites circunscritos da crise subprime: análise dos efeitos da crise na volatilidade das ações no novo mercado brasileiro e no prime standard alemão. Dissertação de Mestrado em Administração, Universidade Federal de Uberlândia, Programa de Pós-Graduação em Administração, Uberlândia, MG, Brasil.

Francisco, M. L., \& Santos, D. F. L. (2014). Os efeitos da governança corporativa no desempenho das empresas de energia elétrica do Brasil. Anais do Congresso Nacional de Excelência em Gestão, Niterói. Gestão e Design de Produtos e Serviços para a Sustentabilidade, Niterói, RJ, 2014, 10.

Freitas, G. A. de, Silva, E. M., Oliveira, M. C., de Aquino Cabral, A. C., \& Santos, S. M. dos (2018). Governança Corporativa e Desempenho dos Bancos Listados na B3 em Ambiente de Crise Econômica. Revista Contabilidade, Gestão e Governança, 21(1), 100-119.

Garcia, R. L., \& Tavares, C. K. (2017). Empresa familiar e a governança corporativa: breves apontamentos sobre as estruturas de gestão das empresas familiares. Revista de Estudos $e$ Pesquisas Avançadas do Terceiro Setor, 4(1), 481-516.

Geocze, Z. B. (2010). Níveis diferenciados de governança corporativa e o efeito sobre o risco de suas ações. Revista de Finanças Aplicadas, 1, 1-23. 
Instituto Brasileiro de Geografia e Estatística (IBGE) (2019). Em 2017, PIB cresce 1,3\% e chega a $R \$$ 6,583 trilhões. Recuperado em 06 maio, 2020, de https://agenciadenoticias.ibge.gov.br/agencia-sala-de-imprensa/2013-agencia-denoticias/releases/25921-em-2017-pib-cresce-1-3-e-chega-a-r-6-583-trilhoes

Jensen, M. C., \& Meckling, W. H. (1976). Theory of the firm: Managerial behavior, agency costs and ownership structure. Journal of financial economics, 3(4), 305-360.

Liu, C., Uchida, K., \& Yang, Y. (2012). Corporate governance and firm value during the global financial crisis: Evidence from China. International Review of Financial Analysis, 21, 70-80.

Pitzer, M. (2011). A Influência do nível de governança corporativa no valor de mercado das ações das empresas brasileiras negociadas na Bovespa. Dissertação Mestrado, Universidade Estácio de Sá. Rio de Janeiro, RJ, Brasil.

Rajan, R. G., \& Zingales, L. (1998). Financial dependende and Growth. The American Economic Review. 88 (3), 559-586.

Rocha, G. A. P., Rosário Contani, E. A. do, \& Silva Reco, T. L. da (2017). Governança corporativa e desempenho das ações de empresas do setor de consumo e varejo. Contextus: Revista Contemporânea de economia e gestão, 15(3), 230-252.

Rossetti, J. P., \& Andrade, A. (2014). Governança Corporativa: Fundamentos, Desenvolvimento e Tendências (7a ed.). Atlas.

Santos, A., Botinha, R., \& Lemes, S. (2019). Análise da Value Relevance da demonstração do valor adicionado nos níveis diferenciados de governança corporativa da BM\&FBOVESPA. Revista Catarinense da Ciência Contábil, 18, e2697, 1-16.

Silva, A. L. C. da (2017). Governança corporativa e sucesso empresarial. Editora Saraiva.

Silva, C. A. (2018). Breve panorama sobre o setor de comércio no Brasil. Recuperado em 06 maio, 2020, de https://economiadeservicos.com/2018/06/12/breve-panorama-sobre-o-setorde-comercio-no-brasil/

Silva, F. B., Santos, D. F. L., \& Rodrigues, S. V. (2016). Desempenho comparativo de empresas com governança corporativa entre os setores bancário e industrial. RAUnP, 8(2), 48-65.

Silveira, A. D. M. D. (2002). Governança corporativa, desempenho e valor da empresa no Brasil. Doctoral dissertation, Universidade de São Paulo, São Paulo, SP, Brasil.

Silveira, A. D. M. D. (2004). Governança corporativa e estrutura de propriedade: determinantes e relação com o desempenho das empresas no Brasil. Tese de Doutorado em Administração, Faculdade de Economia, Administração e Contabilidade, Universidade de São Paulo, São Paulo, SP, Brasil.

Srour, G. (2005). Práticas diferenciadas de governança corporativa: um estudo sobre a conduta e a performance das firmas brasileiras. Revista Brasileira de Economia, 59(4), 635-674. 